\title{
Partial T and B lymphocyte immunodeficiency and predisposition to lymphoma in patients with hypomorphic mutations in Artemis
}

\author{
Despina Moshous, ${ }^{1}$ Christophe Pannetier ${ }^{2}$ Régina de Chasseval, ${ }^{1}$ Françoise le Deist, ${ }^{1}$ \\ Marina Cavazzana-Calvo, ${ }^{1}$ Serge Romana, ${ }^{3}$ Elizabeth Macintyre,${ }^{4}$ Danielle Canioni,${ }^{5}$ \\ Nicole Brousse, ${ }^{5}$ Alain Fischer, ${ }^{1,6}$ Jean-Laurent Casanova, ${ }^{6,7}$ and Jean-Pierre de Villartay ${ }^{1}$ \\ ${ }^{1}$ Unité Développement Normal et Pathologique du Système Immunitaire, Institut National de la Santé et de la Recherche \\ Médicale (INSERM) U429, Hôpital Necker Enfants-Malades, Paris, France \\ ${ }^{2}$ Unité de Biologie du Gène, Institut Pasteur, Paris, France \\ ${ }^{3}$ Laboratoire de Cytogénétique, \\ ${ }^{4}$ Laboratoire d'Hématologie, \\ ${ }^{5}$ Laboratoire d'Anatomie Pathologique, and \\ ${ }^{6}$ Unité d'Immunologie et Rhumatologie Pédiatrique, Hôpital Necker, Paris, France \\ ${ }^{7}$ Laboratoire de Génétique Humaine des Maladies Infectieuses, INSERM U550, Faculté Necker, Paris, France
}

\begin{abstract}
We have previously described the identification of Artemis, a factor involved in the nonhomologous end joining (NHEJ) phase of $\mathrm{V}(\mathrm{D}) \mathrm{J}$ recombination of $\mathrm{T}$ and $\mathrm{B}$ cell receptor genes. Null mutations of the Artemis gene result in a complete absence of $\mathrm{T}$ and $\mathrm{B}$ lymphocytes that is associated with increased cell radiosensitivity, causing the radiosensitive $\mathrm{T}^{-} \mathrm{B}^{-}$SCID (RS-SCID) condition. We presently report the occurrence of hypomorphic mutations of the Artemis gene in four patients from two kindreds. Partially preserved in vivo activity of Artemis is associated with the presence of polyclonal $\mathrm{T}$ and $\mathrm{B}$ lymphocyte populations, albeit in reduced numbers, along with chromosomal instability and development of EBV-associated lymphoma in two of four patients. This syndrome emphasizes the role of Artemis in the NHEJ pathway of DNA repair and suggests that other, yet ill-defined, conditions associating immunodeficiency and lymphoma could be caused by mutations in genes encoding NHEJ factors.
\end{abstract}

J. Clin. Invest. 111:381-387 (2003). doi:10.1172/JCI200316774.

\section{Introduction}

$\mathrm{V}(\mathrm{D}) \mathrm{J}$ recombination, the molecular process responsible for the diversity of Ig and T cell receptors (TCRs), is initiated by a DNA double-strand break (dsb) mediated by the lymphoid-specific factors RAG1 and RAG2 (1). The DNA-repair machinery that resolves DNA dsb belongs to the nonhomologous end joining (NHEJ) pathway. At least five proteins, the Ku70/Ku80/DNAPKcs complex and the XRCC4/DNA ligase IV complex, participate in NHEJ (2). All animals carrying a genetic

\section{Received for publication August 28, 2002, and accepted in revised form} November 19, 2002.

Address correspondence to: Jean-Pierre de Villartay, INSERM U429, Hôpital Necker Enfants-Malades, 149 rue de Sèvres, 75015 Paris, France. Phone: 33-01-44-49-50-81; Fax: 33-01-42-73-06-40; E-mail: devillar@infobiogen.fr.

Alain Fischer and Jean-Laurent Casanova contributed equally to this work.

Conflict of interest: The authors have declared that no conflict of interest exists.

Nonstandard abbreviations used: $\mathrm{T}$ cell receptor (TCR); doublestrand break (dsb); nonhomologous end joining (NHEJ); radiosensitive $\mathrm{T}^{-} \mathrm{B}^{-}$SCID (RS-SCID); ionizing radiation (IR); ataxia-telangectasia (AT); Nijmegen breakage syndrome (NBS); latent membrane protein of EBV (LMP1); Epstein-Barr early region (EBER); bone marrow transplantation (BMT); complementary determining region 3 (CDR3). defect in one of the $V(D) J$ recombination factors, either natural (murine and equine scid) or engineered through homologous recombination, exhibit a profound defect in early lymphoid development due to defective $V(D) J$ recombination (3-13).

Artemis, a new actor in the NHEJ apparatus, is a critical component of the $\mathrm{V}(\mathrm{D}) \mathrm{J}$ recombinase machinery (14). Mutations in the Artemis gene cause RS-SCID in humans. Artemis belongs to the metallo- $\beta$-lactamase superfamily, together with other DNA-repair factors (15). It has recently been reported that Artemis, following its association with, and phosphorylation by, DNA-PKcs, can open the Rag1/2-generated hairpin structures at the dsb (16). All mutations identified to date in the Artemis gene are loss-of-function mutations resulting in the complete absence of peripheral B and T lymphocytes (14).

DNA dsb can be formed during $\mathrm{V}(\mathrm{D}) \mathrm{J}$ recombination or DNA replication, or induced by oxygen free radicals or ionizing radiation (IR). Failure to properly repair DNA dsb results in genomic instability leading to neoplasia (17). Several inherited disorders in humans, such as ataxia-telangectasia (AT) and Nijmegen breakage syndrome (NBS), are characterized by an immune deficiency and an impaired cellular response to DNA damage associated with a high risk of cancer, mainly lymphoid malignancies (18). Increased susceptibility to 
lymphoid malignancies in AT and NBS is accompanied by a predisposition to chromosome translocations, which usually involve Ig or TCR loci on one hand, and protooncogenes such as c-myc on the other hand (19). The genes involved in these disorders (ATM and NBS1, respectively) therefore appear to participate in monitoring genomic integrity and, as such, are considered tumor-suppressor genes. The development of pro-B cell lymphomas in several animal models of defective NHEJ factors reveals the essential role of these $V(D) J$ recombination/DNA-repair components in the maintenance of genomic stability (20-22). We here describe a new syndrome of combined immunodeficiency and predisposition to B cell lymphoma in humans, caused by hypomorphic mutations of Artemis.

\section{Methods}

Patients and cells. We analyzed four patients (P68, P69, P70, and P72) from two families with a combined immunodeficiency characterized by a severe $\mathrm{T}$ and $\mathrm{B}$ lymphocytopenia (Table 1). P68, P69, and P70 are nonconsanguineous siblings, while $\mathrm{P} 72$ is from a consanguineous family. Studies were performed after informed consent of the families. Primary skin fibroblasts were obtained from P70 and P72 as well as Artemis-deficient SCID patients (P15, P63) and Rag1/2-deficient patients (P62, P13).

Histology. All tissues were fixed in Bouin's or in 10\% neutral formalin and embedded in paraffin. A frozen sample was also available for molecular analysis. H\&E-, Giemsa-, and reticulin-stained sections were prepared from paraffin blocks. Immunohistochemistry was performed on fixed sections with an indirect three-stage method using the antibodies CD20, CD3, Ki67, and LMP1 (latent membrane protein of EBV) from Dakopatts Ab (Copenhagen, Denmark). In situ hybridization of EBV-RNA was performed on formalin-fixed tissue sections as described previously (23), using an Epstein-Barr early region (EBER) probe.

Molecular analysis of clonality by Southern blot and PCR. $\mathrm{IgH}$ gene configuration in $\mathrm{B}$ cell lymphomas was assessed by multiplex PCR from DNA using FR1, FR2, or FR3 consensus VH primers with JH1,2,4,5 consensus, JH3-specific or JH6-specific primers, as previously described (24). Heteroduplex PCR products were analyzed on nondenaturing PAGE and visualized by ethidium bromide staining. Some determinations were confirmed by multifluorescent analysis of PCR products by GENESCAN analysis on an ABI 310 gene analyzer (Applied Biosystems, Foster City, California, USA), using 6-FAM.JH1,2,4,5, HEX.JH3, and TET.JH6, as previously described (25). The sensitivity of detection of a clonal population by these techniques is approximately $1-5 \%$ in a polyclonal background. Southern analysis was performed on BamHI/HindIII- or BglII-digested DNA, hybridized with an IgH JH6 probe.

Cell cycle analysis. Exponentially growing primary skin fibroblasts were subjected to 5 Gy irradiation, followed by a pulse of BrdU incorporation 10 hours after irradi- ation. The determination of cellular proportion in each phase of the cell cycle was assessed by FACS analysis using an anti-BrdU antibody and propidium iodide incorporation for DNA-content measuring.

$T C R$ analysis. T cell V $\beta$ junctions were analyzed by Immunoscope technology as previously described (26). $V(D) J$ recombination. Analysis of $\mathrm{V}(\mathrm{D}) \mathrm{J}$ recombination in fibroblasts was performed as previously described $(14,27)$.

Mutation determination. The analysis of Artemis mutation was carried out on genomic DNA as previously described (14). The translation initiation ATG was reassigned at position 39 of the published Artemis nucleotide sequence, adding seven amino acids to the previous protein sequence.

Radiosensitivity. Artemis-coding regions (either WT or carrying the P70 truncation) were subcloned into the pMND retroviral vector (the generous gift of D. Kohn, Children's Hospital Los Angeles, Los Angeles, California, USA) upstream of an ires-GFP cassette under the regulation of the virus LTR. Retroviral supernatants were produced by transient transfection of Phoenix-Ampho cells (the generous gift of G. Nolan, Stanford University, Stanford, California, USA) as described (28) and used to transduce fibroblasts from P70 and an Artemis-deficient fibroblast line obtained from an RS-SCID patient. Transduced $\left(\mathrm{GFP}^{+}\right)$cells were mixed to a ratio of approximately $10 \%$ with the corresponding untransduced $\left(\mathrm{GFP}^{-}\right)$counterparts, and the resulting mixed populations were subjected to 3 or 4 Gy IR. The number of $\mathrm{GFP}^{+}$cells was then evaluated over time by FACS analysis to assess the selective advantage conferred by the introduction of the various forms of Artemis. The results are presented as the ratio of $\mathrm{GFP}^{+}$to $\mathrm{GFP}^{-}$cells. This ratio is set to 1 at initiation of the culture.

\section{Results}

Clinical characteristics of patients. The first patient, $\mathrm{P} 68$, was a boy who developed candidiasis and protracted diarrhea soon after birth and cervical lymphadenopathies at 9 months of age. X-ray examination of the chest showed nodular lung infiltrates. Biological investigations (Table 1) showed hypogammaglobulinemia involving $\operatorname{IgG}$ and $\operatorname{IgA}$. Autoimmune anemia and thrombocytopenia were observed at disease onset. These features were associated with severe lymphocytopenia (60-120 per microliter). The second patient, P69, a sister of P68, developed oral candidiasis soon after birth as well as recurrent pulmonary and respiratory infections. Lymphocytopenia was first detected on a blood cell count performed at 10 months of age and was constant thereafter. Biological investigations showed low serum IgG and a complete absence of IgA. Intravenous Ig treatment was initiated when she was 10 months old. She received an allogeneic bone marrow transplantation (BMT) from a matched unrelated donor at 5 years of age. The third patient, P70, a sister of P68 and P69, presented similar clinical manifestations. From 1 year of age, recurrent otitis and bronchopneumonia occurred, the latter resulting in bronchiec- 
Table 1

Clinical and biological manifestations

\begin{tabular}{|c|c|c|c|c|c|}
\hline Patients & P68 & P69 & P70 & P72 & Normal values $\mathrm{F}$ \\
\hline $\begin{array}{l}\text { Sex } \\
\text { Consanguinity } \\
\text { Cytogenetic analysis }\end{array}$ & $\begin{array}{c}\text { M } \\
- \\
\text { Trisomy, Chr. } 9\end{array}$ & $\begin{array}{c}\mathrm{F} \\
- \\
\text { Translocation, Chr. 7:14 }\end{array}$ & $\begin{array}{c}\mathrm{F} \\
- \\
\mathrm{ND}\end{array}$ & $\begin{array}{c}\mathrm{F} \\
+ \\
\text { Inversion, Chr. } 7\end{array}$ & \\
\hline $\begin{array}{l}\text { Lymphocyte counts }^{\mathrm{A}} \\
\text { CD3 }^{\mathrm{A}} \\
\text { CD4 }^{\mathrm{A}} \\
\text { CD8 } \\
\text { CD19 } \\
\text { CD16/CD56 }\end{array}$ & $\begin{array}{c}66 \\
8 \\
\text { ND } \\
\text { ND } \\
8 \\
18\end{array}$ & $\begin{array}{c}500-1,100 \\
280-580 \\
145-341 \\
90-290 \\
8-110 \\
227\end{array}$ & $\begin{array}{c}155-610 \\
77-321 \\
21-133 \\
57-212 \\
0-5 \\
60\end{array}$ & $\begin{array}{c}378-748 \\
200-350 \\
134-185 \\
85-115 \\
0-51 \\
\text { ND }\end{array}$ & $\begin{array}{c}2,500-3,500 \\
1,500-2,500 \\
900-2,000 \\
400-1,000 \\
200-600 \\
100-500\end{array}$ \\
\hline $\begin{array}{l}\mathrm{PHA}^{\mathrm{B}} \\
\text { Tetanus toxoid }\end{array}$ & $\begin{array}{l}35.8 \pm 22 \\
59.4 \pm 32\end{array}$ & $\begin{array}{l}26.6 \pm 18 \\
10.0 \pm 8.8\end{array}$ & $\begin{array}{c}16.8 \pm 14.6 \\
3.5 \pm 3.9\end{array}$ & $\begin{array}{l}35.8 \pm 22 \\
59.4 \pm 32\end{array}$ & $\begin{array}{l}>40 \\
>15\end{array}$ \\
\hline $\begin{array}{l}\lg G^{C} \\
\lg A^{C} \\
\lg ^{C}\end{array}$ & $\begin{array}{c}14.4^{\mathrm{E}}(9 \mathrm{mos}) \\
0.18 \\
6.11\end{array}$ & $\begin{array}{c}1.33 \text { (10 mos }) \\
<0.07 \\
0.56 \text { (10 mos })\end{array}$ & $\begin{array}{l}2.91(5 \mathrm{yrs}) \\
<0.06 \\
0.9-3.4\end{array}$ & $\begin{array}{c}2.46(8 \mathrm{yrs}) \\
<0.07 \\
0.43\end{array}$ & $\begin{array}{l}4.2-12.6 \\
0.4-1.6 \\
0.4-1.2\end{array}$ \\
\hline
\end{tabular}

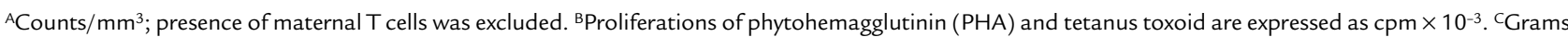
per liter. DP68, P69, and P70 are siblings. EMostly accounted for by an Ig monoclonal component. FNormal values for individuals 10 months to 4 years. Chr., chromosome; ND, not done.

tasis. At 11 years of age, a cerebral abscess caused by Toxoplasma gondii infection was detected. This patient died at 13 years of age of sepsis associated with respiratory failure. Biological investigations detected low serum IgG and absence of IgA. Profound lymphopenia was also noted (Table 1).

In a second family, parents who were first cousins had a son and a daughter who died at 1 month and 2.5 years, respectively. Patient P72 was born with normal body weight and height but developed recurrent pulmonary infections leading to bronchiectasis and failure to thrive at 4 years of age. When she was 7 years old, she presented with cholangitis, liver disease, and protracted diarrhea caused by Cryptosporidium infection. She developed liver cirrhosis, which was fatal at 16 years of age. Biological investigation showed severe lymphopenia involving both $\mathrm{T}$ and $\mathrm{B}$ lymphocytes and hypogammaglobulinemia affecting IgG and IgA. The $\alpha$-fetoprotein level was normal. Patients died of either recurrent infections (P70 and P72) or lymphoma progression (P68 and P69) (see below). Cytogenetic analyses (Table 1) revealed a translocation of chromosomes 7 and 14 and an inversion of chromosome 7 in phytohemagglutinin-activated T cells from P69 and P72 respectively, suggesting a genomic instability in these patients, particularly involving the chromosomes where Ig and TCR genes are located. Such rearrangements of chromosomes harboring the Ig and TCR genes are reminiscent of those observed in patients with AT and NBS conditions (18). AT is a recessive autosomal disorder characterized by cerebellar ataxia, telangectasia, humoral immunodeficiency, and sensitivity to IR. NBS, first described as an AT variant phenotype, lacks ataxia and telangectasia but is accompanied by microcephaly ("birdlike" face phenotype) and major growth retardation. Despite several analogies between patients presented here and AT or NBS patients, none of the patients described here presented with ataxia, telangectasia, "birdlike" face, or growth retardation.

Development of B cell lymphomas. B cell lymphomas (Table 2) developed in two patients in the first family. In P68, a lymphoproliferation was diagnosed by lymph node biopsy examination at 9 months of age. Abnormal $B$ cells could also be detected in blood and cerebrospinal fluid. In spite of treatment by anti-B cell specific mAb's, the patient died 5 days after diagnosis. Autopsy revealed an extensive infiltration of lung, liver, and skeletal muscle. In P69, evidence for active EBV replication in the blood was documented immediately prior to BMT at 5 years by PCR analysis as well as by detection of anti-EBVearly antigen antibodies. A B cell lymphoma of recipient origin localized to the liver was identified 38 days after

Table 2

Immunohistological features of lymphomas in P68 and P69

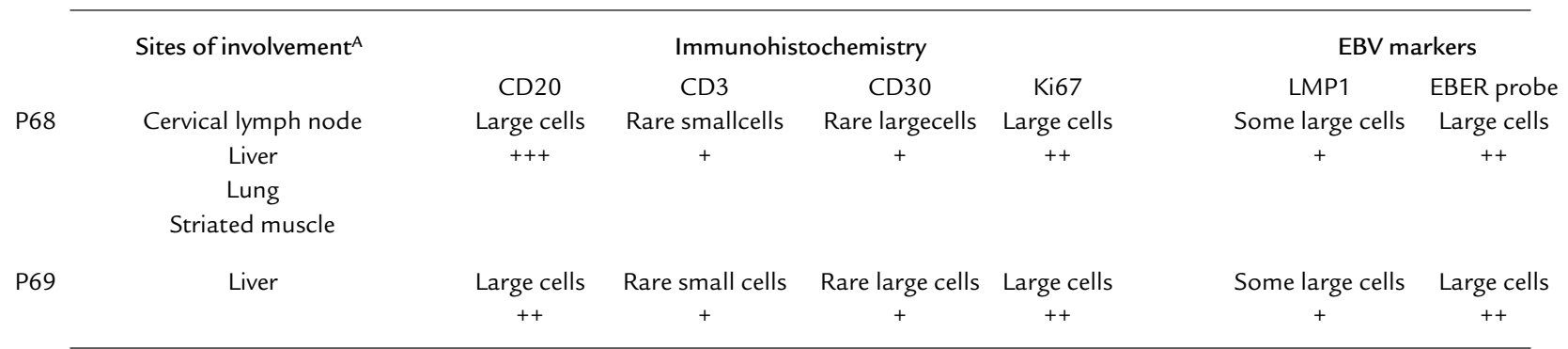

ALymphoproliferation was characterized as large B cells associated with small lymphocytes. 

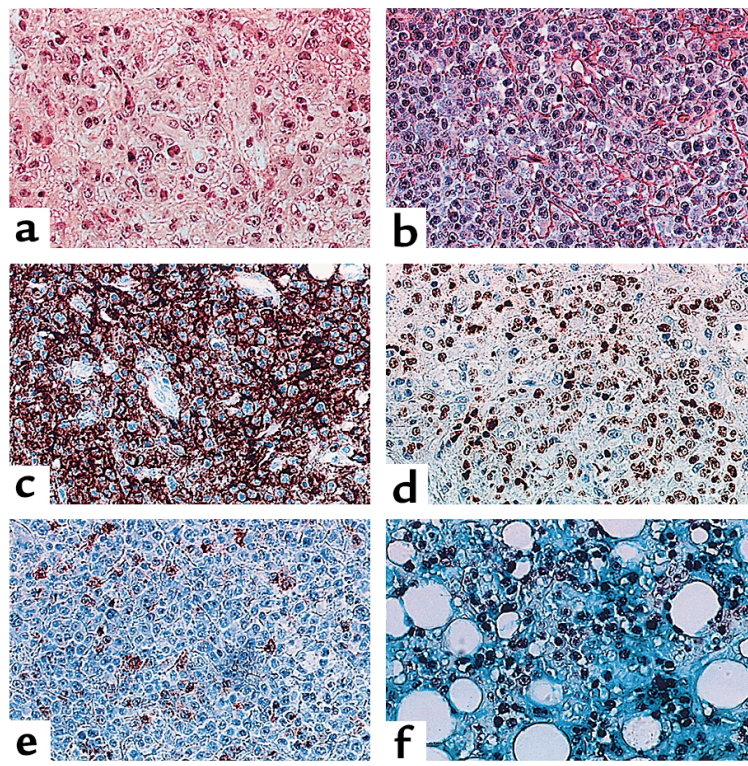

\section{Figure 1}

Immunohistological analysis of B cell lymphomas in P68 and P69. (a) Lymphoproliferation in the liver of P69, showing a lymphoid infiltration with a mixture of large and small lymphocytes. (b-f) Lymphoproliferation in lymph node of P68 stained with H\&E (b), CD20 (c), Ki67 (d), LMP1 (e), and EBER (f). ×40.

BMT; it led to the patient's death 12 days later in spite of treatment with B cell-specific mAb's. Both children presented with a lymphoproliferative syndrome in the liver (Figure 1a), lung, and lymph node (Figure 1b), as well as in muscle in P68. Large B cells expressed CD20 (Figure 1c) and the proliferative marker Ki67 (Figure 1d). A fraction of cells were $\mathrm{LMP1}^{+}$(Figure 1e), while numerous nuclei were stained with an EBER probe (Figure 1f). IgH V(D)J PCR and Southern blot molecular analysis of P68 lymph node biopsy and P69 liver biopsy demonstrated a clonal $\operatorname{IgH}$ proliferation (Figure 2 and data not shown) without evidence of c-myc rearrangement. A trisomy of chromosome 9 was identified in the lymph node biopsy and on spontaneously growing B cells in vitro from P68.

Normal cell cycle checkpoints following IR. One consequence of mutations in both the ATM and NBS1 genes is the absence of critical cell cycle checkpoints following DNA damage, such as those caused by IR (18). As a consequence of IR-induced DNA damage, normal cells undergo cell cycle arrest at both $\mathrm{S}$ and $\mathrm{M}$ phase entry, leading to an accumulation of cells in G2 (Figure 3a). Primary skin fibroblasts from P70 exhibited sensitivity to IR (see below), but no defect in cell cycle checkpoints was observed. Indeed, the proportion of P70 cells dropped sharply in $S$ phase, while accumulating in G2 following 5 Gy IR (Figure 3b), unlike AT cells (Figure $3 c$ ), which continue progression to $S$ phase following IR. These clinical and biological observations clearly distinguish this phenotype from AT and NBS. In addition, the segregation analysis of relevant polymorphic markers in the P68/69/70 family formally excluded $A T M$ and NBS1 genes (data not shown).
Impaired $V(D) J$ recombination. Because of the increased sensitivity of patient cells to IR, we sought a defect in the NHEJ DNA-repair machinery. We examined TCR$\beta \mathrm{V}(\mathrm{D}) \mathrm{J}$ junctions in lymphocytes from P69 and P70. Immunoscope studies (Figure $4 a$ ), which analyze the distribution of complementary determining region 3 (CDR3) length, spanning the V(D)J junction of TCR- $\beta$ transcripts (26), revealed a Gaussian distribution in $T$ lymphocytes of P69 and P70. Of note, CDR3 lengths were constantly shorter by about one amino acid for the three $V \beta$ families tested $(V \beta 2, V \beta 5$, and $V \beta 6$ ) (Figure $4 \mathrm{a}$, solid line) as compared with those in control lymphocytes (dashed line). Sequencing analysis indicated that this shift was the consequence of a virtual absence of $\mathrm{N}$ nucleotide addition at the $\mathrm{V}(\mathrm{D}) \mathrm{J}$ junctions (Figure $4 \mathrm{~b}$ ). Whereas $85 \%$ of junctions from control $\mathrm{T}$ cells contained from zero to eight nontemplated nucleotides on either side of the $\mathrm{D} \beta$ segments (mean 3.3 nucleotides), in T lymphocytes from $\mathrm{P} 69$ and $\mathrm{P} 70$, only two junctions out of 16 had $\mathrm{N}$ nucleotides (one and two $\mathrm{N}$ nucleotides, respectively). Since absence of $\mathrm{N}$ diversity is a characteristic of Ku80-/- mice (29), V(D) J recombination was analyzed on extrachromosomal substrate in patients' fibroblasts (Table 3). Despite the presence of a few $\mathrm{B}$ and $\mathrm{T}$ lymphocytes in vivo, no coding-joint formation could be recovered from P70 fibroblasts; this defect is a characteristic of Artemisdeficient cell lines $(14,27)$ (e.g., RS-SCID patients P15 and $\mathrm{P} 63$ in Table 3). The complementation of the $\mathrm{V}(\mathrm{D}) \mathrm{J}$ recombination deficiency by addition of exogenous WT Artemis in P70 cells suggested that an Artemis-gene defect was responsible for the immunodeficiency in this family. $V(D) J$ recombination in fibroblasts from P72 was also diminished and likewise restored by addition of exogenous Artemis (Table 3).

Mutations in Artemis. Sequencing the Artemis gene demonstrated that P68, P69, and P70 were compound heterozygotes. One allele harbored a genomic deletion of exons 1-3, leading to an absence of Artemis mRNA expression, a loss-of-function mutation previously

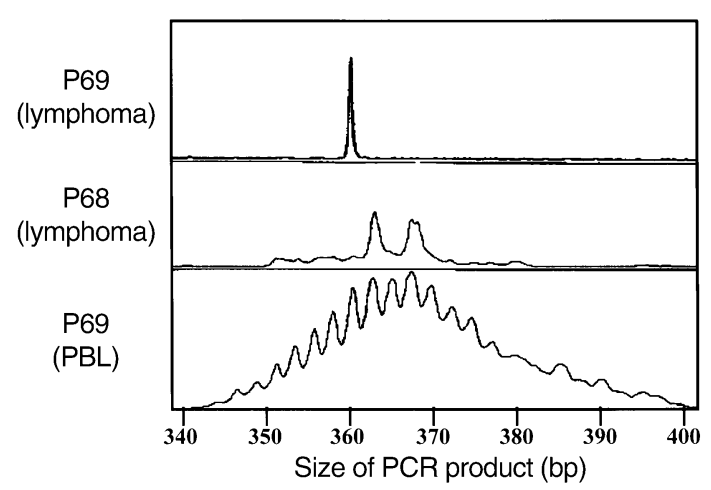

\section{Figure 2}

Clonality of B cell lymphomas in P68 and P69. IgH V(D)J genescan profiles from liver biopsy (top, clonal monoallelic) and peripheral blood lymphocytes (PBL) (bottom, polyclonal) from P69 and lymph node (middle, clonal biallelic) from P68 DNA, amplified with FR1 primer. The size of PCR products is indicated. 


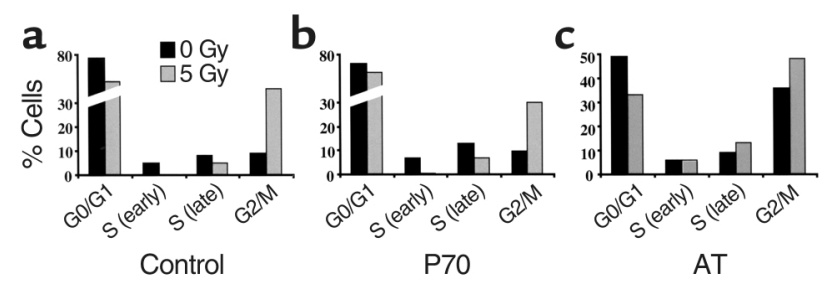

Figure 3

Cell cycle analysis following $\gamma$-ray irradiation. Primary skin fibroblasts from a control (a), a P70 (b), and an AT patient (c) were analyzed for the presence of the $S$ and $G 2$ cell cycle checkpoints following 5 Gy IR. Results are expressed as the percentage of cells present in each phase of the cell cycle during BrdU pulse staining 10 hours after irradiation. The various phases of the cell cycle were determined by measurement of DNA content (propidium iodide staining).

described in RS-SCID patients (14). The second allele harbored a seven-nucleotide deletion (T1384-A1390) in exon 14 , resulting in a frameshift at $\mathrm{D} 451$ followed by a premature stop codon ten amino acids downstream. In P72, a homozygous deletion of 17 nucleotides in exon 14 (A1328-T1344) was identified. It resulted in a frameshift at T432 followed by a premature stop codon 15 amino acids downstream. The defect detected in the $\mathrm{V}(\mathrm{D}) \mathrm{J}$ recombination assay in P70, more profound than the one in P72, possibly resulted from the presence of a null allele in this patient. Retroviral gene transfer of a WT Artemis-ires-GFP construct complemented the increased radiosensitivity in primary fibroblasts from
P70 as shown by the rise in the $\mathrm{GFP}^{+} / \mathrm{GFP}^{-}$ratio, initially set to 1 , demonstrating selective advantage of $\mathrm{GFP}^{+}$cells over nontransduced, GFP- cells following 3 Gy IR (Figure 5a). The overexpression of WT Artemis in P70 and RS-SCID cells did not result, on its own, in growth advantage in the absence of irradiation, as shown by the stable $\mathrm{GFP}^{+} / \mathrm{GFP}^{-}$ratio. Introduction of the truncated form of Artemis identified in P70 (ArteP70) into fibroblasts from a fully Artemis-deficient cell line demonstrated a partial protective effect (Figure $5 b)$. These results indicate that an Artemis protein lacking about one-third of its C-terminal domain still retains a residual activity. It is noteworthy that these mutations of exon 14 spare the metallo- $\beta$-lactamase region of Artemis, thought to represent the catalytic domain of the protein $(14,30)$. This contrasts with mutations in RS-SCID patients, which always affect the metallo- $\beta$-lactamase domain. Altogether, these results indicate that, depending on Artemis mutations, null or hypomorphic phenotypes result in either $\mathrm{T}^{-} \mathrm{B}^{-} \mathrm{RS}-\mathrm{SCID}$ or partial $\mathrm{T}^{+} \mathrm{B}^{+}$immune deficiency with genomic instability and lymphoma.

\section{Discussion}

We herein describe a new syndrome of immunodeficiency caused by hypomorphic mutations in the Artemis gene. The mutations resulted in truncations of the Artemis protein in the last exon, leaving intact the metallo- $\beta$-lactamase domain, in both studied kindreds.

$\mathbf{a}$

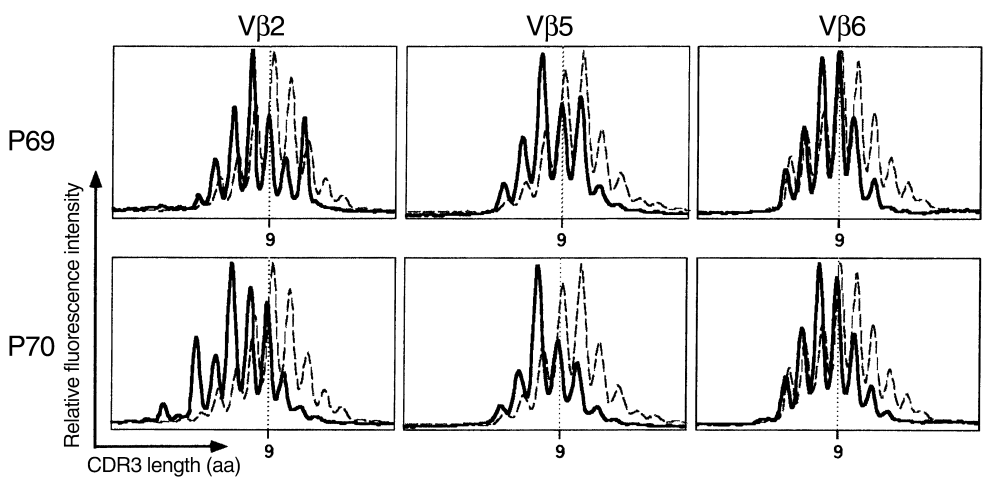

$\begin{array}{lll}\text { b } \quad V B & N \\ V \beta 2 \text { germ TGC AGT GCT AGA GA }\end{array}$

VB2germ TGC AGT GCT AGA GA

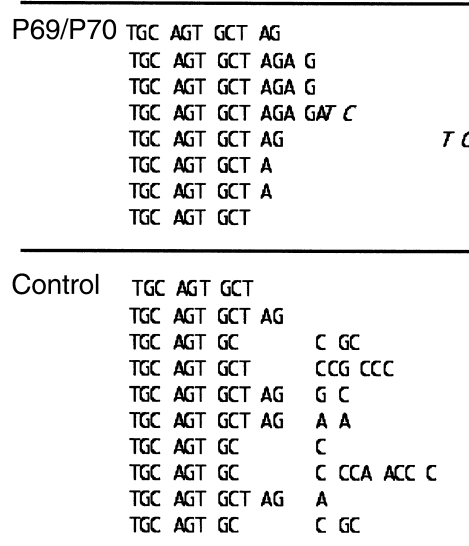

\begin{abstract}
$\mathrm{D} \beta \quad \mathrm{N}$
\end{abstract}

G ACA GGG
GG ACA GG
GG ACA GGG GG
GG GG
CA GGG ACT AGC CT
GG GGG ACT AG
GAC AA

$\mathrm{N}$

$\begin{array}{ll}\text { GGA C } & \text { CA } \\ \text { G G } & \text { TC TA } \\ \text { A CA } & \text { C AAA } \\ \text { GCG GG } & \text { C GCA CG } \\ \text { GA CTA GCG } & \text { GTC TC } \\ \text { GG GAC AG } & \text { C TCG TCT } \\ \text { GGG GG } & \text { G AGC TI } \\ \text { GG GG } & \text { T AC } \\ \text { GAC AGG GG } & \\ \text { G ACA GG } & \text { A CC }\end{array}$

$\mathrm{J} \beta \quad \mathrm{N}$ nucleotides

\section{Figure 4}

TCR- $\beta$ junction analysis. (a) TCR CDR3-length profile of $\mathrm{V} \beta 2, \mathrm{~V} \beta 5$, and $\mathrm{V} \beta 6$ cell populations in lymphocytes from P69 and P70 (solid lines) and control (dashed lines). Determination was performed by the Immunoscope method. The relative intensity of the bands ( $y$ axis) was plotted as a function of CDR3 size. (b) Sequence of TCR- $\beta$ V(D)J junctions for $V \beta 2$ in lymphocytes from P69, P70, and control. P nucleotides are represented in italics. 
Table 3

Defective $V(D)$ J coding-joint formation in fibroblasts

\begin{tabular}{|c|c|c|c|c|c|}
\hline \multirow[b]{2}{*}{ Cell line } & \multirow[b]{2}{*}{$\begin{array}{l}\text { Artemis } \\
\text { plasmid }\end{array}$} & \multicolumn{4}{|c|}{ Coding-joint substrate ( $\mathrm{pHRecCJ})$} \\
\hline & & Blue col. & Total col. & $\mathrm{R}^{\mathrm{A}}$ & $\begin{array}{c}\text { Fold } \\
\text { complementatic }\end{array}$ \\
\hline \multicolumn{6}{|l|}{ WT } \\
\hline P62 & $\begin{array}{l}- \\
+\end{array}$ & $\begin{array}{l}13 \\
29\end{array}$ & $\begin{array}{c}9,100 \\
22,000\end{array}$ & $\begin{array}{l}4.28 \\
3.95\end{array}$ & 0.92 \\
\hline P13 & $\begin{array}{l}- \\
+\end{array}$ & $\begin{array}{l}26 \\
56\end{array}$ & $\begin{array}{l}18,000 \\
21,600\end{array}$ & $\begin{array}{l}4.33 \\
7.77\end{array}$ & 1.79 \\
\hline \multicolumn{6}{|c|}{ RS-SCID } \\
\hline P15 & $\begin{array}{l}- \\
+\end{array}$ & $\begin{array}{c}0 \\
85\end{array}$ & $\begin{array}{c}30,000 \\
7,700\end{array}$ & $\begin{array}{l}<0.03 \\
33.11\end{array}$ & $>330$ \\
\hline P63 & $\begin{array}{l}- \\
+\end{array}$ & $\begin{array}{c}0 \\
30\end{array}$ & $\begin{array}{c}177,000 \\
53,000\end{array}$ & $\begin{array}{c}<0.005 \\
1.70\end{array}$ & $>100$ \\
\hline \multicolumn{6}{|l|}{ Patients } \\
\hline P70 & $\begin{array}{l}- \\
+\end{array}$ & $\begin{array}{c}0 \\
23\end{array}$ & $\begin{array}{l}64,800 \\
48,800\end{array}$ & $\begin{array}{c}<0.01 \\
1.41\end{array}$ & $>30$ \\
\hline P72 & $\dot{-}+$ & $\begin{array}{c}6 \\
52\end{array}$ & $\begin{array}{l}30,260 \\
15,500\end{array}$ & $\begin{array}{c}0.59 \\
10.06\end{array}$ & 17 \\
\hline
\end{tabular}

Hypomorphic mutations in NHEJ proteins encoding genes have also been described in DNA ligase IV (31). While complete DNA ligase IV KO is embryonic-lethal in mice $(9,10)$, development of both $B$ and $T$ lymphocytes can occur in DNA ligase IV-deficient patients with hypomorphic mutations. Similarly, hypomorphic mutations of the Artemis gene are compatible with low-level in vivo $V(D) J$ recombination, as shown by the presence of both polyclonal B and $\mathrm{T}$ lymphocytes in these patients. The residual activity of Artemis translates into an absence of $\mathrm{N}$ diversity at the $\mathrm{V}(\mathrm{D}) \mathrm{J}$ junctions in these $\mathrm{T}$ cells, a situation reminiscent of that observed in $\mathrm{Ku} 86 \mathrm{KO}$ mice $(29,32)$. This suggests a possible requirement (and interaction?) for Artemis in the recruitment of TdT at the coding ends. A functional/physical association between TdT and NHEJ factors has already been described in the case of the Ku70/Ku80/DNAPKcs complex $(33,34)$. It is thus anticipated that further analysis of as-yet undefined immunodeficient conditions could be of interest in trying to identify missense mutants of Artemis, since such mutants are generally very informative regarding precise protein function. Variability in lymphoid phenotypes, including null versus hypomorphic mutations, is reminiscent of the consequences of null versus hypomorphic mutations in the Rag1 and Rag2 genes. Several mutations with residual activities in the Rag1 and Rag2 genes have been documented in humans, where they cause either SCID with very low counts of B and T cells or Omenn syndrome $(35,36)$.

One intriguing observation of this study was the association of the partial Artemis deficiency with the development of aggressive EBV-associated B cell lymphoma in two of the four patients. Although we cannot formally exclude that the immunodeficiency has favored the development of uncontrolled EBV-driven B cell proliferation, the malignant origin is, however, very likely, as is supported by several pieces of evidence.
Firstly, B cell proliferations were clonal in both cases, as assessed by IgH gene rearrangement studies, while nonmalignant EBV proliferative syndromes are generally polyclonal. Secondly, a clonal chromosomal alteration was detected in lymphoma cells from P68 (clonal trisomy of chromosome 9). Chromosomal alterations are commonly associated with hematological malignancies (19). Lastly, the onset of these two lymphomas occurred in the context of a general genomic instability, as documented in three of the four patients. According to the hypothesis of Kinzler and Vogelstein (37), neoplastic transformation results from the combined defects in factors belonging to the two families of DNA-repair factors, "gatekeepers" and "caretakers." Gatekeepers are proteins involved in the control of cellular proliferation and apoptosis. They represent the first line of response to DNA damage by inducing cell cycle arrest. The most well-known factor is the P53 protein. Caretakers, on the other hand, are proteins directly involved in the repair of the lesions and therefore guarantee genomic stability. The development of animal models has been highly instrumental in demonstrating the genomic caretaker role of NHEJ factors (20-22). Indeed, the targeted inactivation, on a $\mathrm{P} 53^{-/-}$ background, of the five previously recognized factors of the NHEJ apparatus involved in $\mathrm{V}(\mathrm{D}) \mathrm{J}$ recombination invariably results in the emergence of aggressive, rapidly fatal, disseminated pro-B cell lymphomas, associated with a profound genetic instability $(21,38,39)$. The parallel between these NHEJ KO animal models and the Artemis-deficient SCID patients described herein is striking and suggests that Artemis may represent a genome guardian as well. Generation of Artemis ${ }^{-/-}$mice on a $\mathrm{P} 53^{-/}$background should help to clarify this important issue.

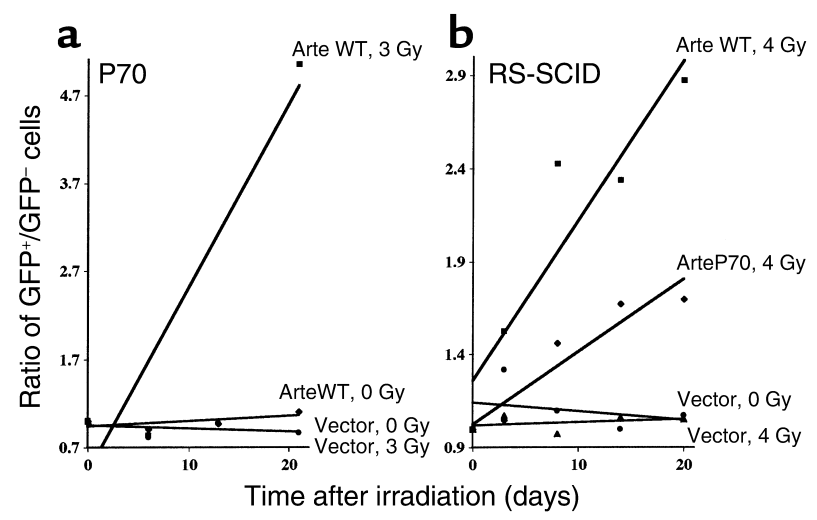

Figure 5

Complementation of IR sensitivity. (a) Fibroblasts from P70 were complemented with WT Artemis. The selective advantage of transduced cells after 3 Gy IR was assessed over time. The control curves, (vector $0 \mathrm{~Gy}$ ) and (vector $3 \mathrm{~Gy}$ ), are superimposed. (b) Fibroblasts from an Artemis-deficient patient were complemented with either the WT or the P70-specific truncated form of Artemis. The selective advantage of transduced cells after 4 Gy IR was assessed over time. Results are expressed as the GFP $/ \mathrm{GFP}^{-}$cell ratio over time following irradiation. 
The observation of hypomorphic mutations of Artemis associated with immunodeficiency and lymphoma suggests that other, similar, ill-defined conditions in humans could be caused by mutations in DNArepair factor-encoding genes also involved in $\mathrm{V}(\mathrm{D}) \mathrm{J}$ recombination. For example, many mutations in the Rag1 and Rag2 genes causing SCID have been analyzed in vitro and found to affect distinct steps of the initial phases of the $\mathrm{V}(\mathrm{D}) \mathrm{J}$ recombination process (40-42). As oncogenic DNA rearrangements can be caused by illegitimate $V(D) J$ recombination, one would argue that patients harboring hypomorphic mutations in either Rag1 or Rag2 may be prone to lymphoma development.

Note added in proof. While this manuscript was being edited for publication, S. Rooney et al. (43) described a spontaneous chromosomal instability in fibroblasts from Artemis $\mathrm{KO}$ mice, accrediting the notion that Artemis is a genomic caretaker.

\section{Acknowledgments}

We thank D. Kohn for the pMND vector and G. Nolan for the Phoenix-Ampho cell line. This work was supported by institutional grants from INSERM and from the Ministère de la Recherche et de la Technologie, as well as grants from the European Community (QLQ1-CT-200101395), the Commissariat à l'Energie Atomique (LRC-7), the Association de Recherche sur le Cancer, and the Louis Jeantet Fondation. D. Moshous is supported by grants from the Association de Recherche sur le Cancer and the Fondation pour la Recherche Médicale.

1. Fugmann, S.D., Lee, A.I., Shockett, P.E., Villey, I.J., and Schatz, D.G. 2000 The RAG proteins and V(D)J recombination: complexes, ends, and transposition. Annu. Rev. Immunol. 18:495-527.

2. Lieber, M.R. 1999. The biochemistry and biological significance of nonhomologous DNA end joining: an essential repair process in multicellular eukaryotes. Genes Cells. 4:77-85.

3. Mombaerts, P., et al. 1992. RAG-1 deficient mice have no mature B and T lymphocytes. Cell. 68:869-877.

4. Shinkai, Y., et al. 1992. RAG-2 deficient mice lack mature lymphocytes owing to inability to initiate V(D)J rearrangement. Cell. 68:855-867.

5. Nussenzweig, A., et al. 1996. Requirement for Ku80 in growth and immunoglobulin V(D)J recombination. Nature. 382:551-555.

6. Zhu, C., Bogue, M.A., Lim, D.S., Hasty, P., and Roth, D.B. 1996. Ku86-deficient mice exhibit severe combined immunodeficiency and defective processing of V(D)J recombination intermediates. Cell. 86:379-389.

7.Jhappan, C., Morse, H.C., 3rd, Fleischmann, R.D., Gottesman, M.M., and Merlino, G. 1997. DNA-PKcs: a T-cell tumour suppressor encoded at the mouse scid locus. Nat. Genet. 17:483-486.

8. Shin, E.K., Perryman, L.E., and Meek, K. 1997. A kinase-negative mutation of DNA-PKCS in equine SCID results in defective coding and signal joint formation. J. Immunol. 158:3565-3569.

9. Barnes, D.E., Stamp, G., Rosewell, I., Denzel, A., and Lindahl, T. 1998. Targeted disruption of the gene encoding DNA ligase IV leads to lethality in embryonic mice. Curr. Biol. 31:1395-1398.

10. Frank, K.M., et al. 1998. Late embryonic lethality and impaired V(D)J recombination in mice lacking DNA ligase IV. Nature. 396:173-177.

11. Gao, Y., et al. 1998. A targeted DNA-PKcs-null mutation reveals DNA-PKindependent functions for $\mathrm{KU}$ in $\mathrm{V}(\mathrm{D}) \mathrm{J}$ recombination. Immunity. 9:367-376.

12. Gao, Y., et al. 1998. A critical role for DNA end-joining proteins in both lymphogenesis and neurogenesis. Cell. 95:891-902.

13. Taccioli, G.E., et al. 1998. Targeted disruption of the catalytic subunit of the DNA-PK gene in mice confers severe combined immunodeficiency and radiosensitivity. Immunity. 9:355-366.

14. Moshous, D., et al. 2001. ARTEMIS, a novel DNA double-strand break repair / V(D)J recombination protein, is mutated in human severe combined immune deficiency. Cell. 105:177-186.
15. Aravind, L. 1997. An evolutionary classification of the matallo- $\beta$-lactamase fold. In Silico Biol. 1:69-91.

16. Ma, Y., Pannicke, U., Schwarz, K., and Lieber, M.R. 2002. Hairpin opening and overhang processing by an Artemis/DNA-dependent protein kinase complex in nonhomologous end joining and V(D)J recombination. Cell. 108:781-794.

17. Pierce, A.J., et al. 2001. Double-strand breaks and tumorigenesis. Trends Cell Biol. 11:S52-S59.

18. Shiloh, Y. 1997. Ataxia-telangiectasia and the Nijmegen breakage syndrome: related disorders but genes apart. Annu. Rev. Genet. 31:635-662.

19. Vanasse, G.J., Concannon, P., and Willerford, D.M. 1999. Regulated genomic instability and neoplasia in the lymphoid lineage. Blood. 94:3997-4010.

20. Ferguson, D.O., and Alt, F.W. 2001. DNA double strand break repair and chromosomal translocation: lessons from animal models. Oncogene. 20:5572-5579.

21. Zhu, C., et al. 2002. Unrepaired DNA breaks in p53-deficient cells lead to oncogenic gene amplification subsequent to translocations. Cell. 109:811-821.

22. Difilippantonio, M.J., et al. 2002. Evidence for replicative repair of DNA double-strand breaks leading to oncogenic translocation and gene amplification. J. Exp. Med. 196:469-480.

23. Kingma, D.W., et al. 1994. Epstein-Barr virus is infrequently identified in non-Hodgkin's lymphomas associated with Hodgkin's disease. Am. J. Surg. Pathol. 18:48-61.

24. Aubin, J., et al. 1995. Description of a novel FR1 IgH PCR strategy and its comparison with three other strategies for the detection of clonality in B cell malignancies. Leukemia. 9:471-479.

25. Brumpt, C., et al. 2000. The incidence of clonal T-cell receptor rearrangements in B-cell precursor acute lymphoblastic leukemia varies with age and genotype. Blood. 96:2254-2261.

26. Pannetier, C., et al. 1993 . The sizes of the CDR3 hypervariable regions of the murine T-cell receptor beta chains vary as a function of the recombined germ-line segments. Proc. Natl. Acad. Sci. USA. 90:4319-4323.

27. Nicolas, N., et al. 1998. A human SCID condition with increased sensitivity to ionizing radiations and impaired $\mathrm{V}(\mathrm{D}) \mathrm{J}$ rearrangements defines a new DNA recombination/repair deficiency. J. Exp. Med. 188:627-634.

28. Pear, W.S., Nolan, G.P., Scott, M.L., and Baltimore, D. 1993. Production of high-titer helper-free retroviruses by transient transfection. Proc. Natl. Acad. Sci. USA. 90:8392-8396.

29. Bogue, M.A., Wang, C.Y., Zhu, C.M., and Roth, D.B. 1997. V(D)J recombination in Ku86-deficient mice: distinct effects on coding, signal, and hybrid joint formation. Immunity. 7:37-47.

30. Callebaut, I., Moshous, D., Mornon, J.P., and De Villartay, J.P. 2002. Metallo- $\beta$-lactamase fold within nucleic acids processing enzymes: the $\beta$-CASP family. Nucleic Acids Res. 30:3592-3601.

31. O'Driscoll, M., et al. 2001. DNA ligase IV mutations identified in patients exhibiting developmental delay and immunodeficiency. Mol. Cell. 8:1175-1185.

32. Purugganan, M.M., Shah, S., Kearney, J.F., and Roth, D.B. 2001. Ku80 is required for addition of $\mathrm{N}$ nucleotides to $\mathrm{V}(\mathrm{D}) \mathrm{J}$ recombination junctions by terminal deoxynucleotidyl transferase. Nucleic Acids Res. 29:1638-1646.

33. Mahajan, K.N., et al. 1999. Association of terminal deoxynucleotidyl transferase with Ku. Proc. Natl. Acad. Sci. USA. 96:13926-13931.

34. Mickelsen, S., et al. 1999. Modulation of terminal deoxynucleotidyltransferase activity by the DNA-dependent protein kinase. J. Immunol. 163:834-843.

35. Corneo, B., et al. 2001. Identical mutations in RAG1 and RAG2 genes leading to defective $V(D) J$ recombinase activity can cause either T-B-severe combined immune deficiency or Omenn syndrome. Blood. 97:2772-2776.

36. Villa, A., et al. 2001. V(D)J recombination defects in lymphocytes due to RAG mutations: severe immunodeficiency with a spectrum of clinical presentations. Blood. 97:81-88.

37. Kinzler, K.W., and Vogelstein, B. 1997. Cancer-susceptiibility genes. Gatekeepers and caretakers. Nature. 386:761, 763 .

38. Ferguson, D.O., et al. 2000. The nonhomologous end-joining pathway of DNA repair is required for genomic stability and the suppression of translocations. Proc. Natl. Acad. Sci. USA. 97:6630-6633.

39. Difilippantonio, M.J., et al. 2000. DNA repair protein Ku80 suppresses chromosomal aberrations and malignant transformation. Nature. 404:510-514.

40. Fugmann, S.D., and Schatz, D.G. 2001. Identification of basic residues in RAG2 critical for DNA binding by the RAG1-RAG2 complex. Mol. Cell. 8:899-910.

41. Qiu, J.X., Kale, S.B., Yarnell Schultz, H., and Roth, D.B. 2001. Separation-offunction mutants reveal critical roles for RAG2 in both the cleavage and joining steps of V(D)J recombination. Mol. Cell. 7:77-87.

42. Huye, L.E., Purugganan, M.M., Jiang, M.M., and Roth, D.B. 2002. Mutational analysis of all conserved basic amino acids in RAG-1 reveals catalytic, step arrest, and joining-deficient mutants in the V(D)J recombinase. Mol. Cell. Biol. 22:3460-3473.

43. Rooney, S., et al. 2002. Leaky scid phenotype associated with defective V(D)J coding end processing in Artemis-deficient mice. Mol. Cell. 10:1379-1390. 